\title{
Local Blood Supply Chain Optimization: A Case Study
}

\author{
Reza Babazadeh $^{1,{ }^{*}}$, Ali Sabbaghnia ${ }^{2}$ and Fatemeh Shafipour ${ }^{1}$ \\ ${ }^{1}$ Faculty of Engineering, Urmia University, Urmia, Iran \\ ${ }^{2}$ School of Industrial Engineering, College of Engineering, University of Tehran, Tehran, Iran \\ "Corresponding author: Faculty of Engineering, Urmia University, Urmia, Iran. Tel: +98-4432972854; Fax: +98-4432773591, Email: r.babazadeh@urmia.ac.ir
}

Received 2020 April 18; Revised 2020 December 06; Accepted 2020 December 06

\begin{abstract}
Blood and its products play an undeniable role in human life. In recent years, although both academics and practitioners have investigated blood-related problems, further enhancement is still warranted. In this study, a mixed-integer linear programming model was proposed for local blood supply chain management. A supply network, including temporary and fixed blood donation facilities, blood banks, and blood processing centers, was designed regarding the deteriorating nature of blood. The proposed model was applied in a real case in Urmia, Iran. The numerical results and sensitivity analysis of the key model parameters ensured the applicability of the proposed model.
\end{abstract}

Keywords: Blood Supply Chain, Optimization, Mathematical Programming, Supply Chain

\section{Background}

Today, blood transfusion is one of the vital components of healthcare. Despite significant medical advances, there is still no alternative for blood products. Blood supply chain management is one of the major challenges of healthcare systems (1). Efficient management of the blood supply chain can lead to reliable blood supply and reduce the total cost. The need for blood products is severely intensified in unprecedented accidents; therefore, a poor supply system can impose excessive costs on the healthcare system and patients (2). According to statistics, on average, one out of every three people needs a blood transfusion and blood products throughout his/her life, and one person needs a blood transfusion to survive per second (3). Also, evidence suggests that $30 \%$ of deaths are due to unexpected events, such as floods and earthquakes, followed by the lack of timely and adequate blood supply to affected areas.

In Iran, about $2.6 \%$ of Iranians donate blood, and about two million donations are made each year (4). The supply of blood products for emergency transfusion is very important. In 2003, a 6.6-magnitude earthquake struck Bam city in Iran, killing 30,000 people and destroying $85 \%$ of the city's buildings. Although many hospitals had an immediate demand for blood and blood products, of 100,000 blood donations, only 21,000 units were successfully delivered to areas in demand, which indicates the poor blood supply chain in Iran (5). In this study, we reviewed the literature to investigate the strengths and weaknesses of the blood supply chain and to identify the research gap. Interested readers can refer to (6) and (7) for a more detailed literature review.

The network design problem of the blood supply chain is different from other business-oriented problems because of the deteriorative nature of blood. For more details on the design challenges of business-oriented supply chain networks, interested readers can refer to the literature (8-10). In this regard, Pereira (11) used a data envelopment analysis (DEA) model to compare technical efficiency rather than economic efficiency for the establishment of a regional blood center in the United States. Pitocco and Sexton (12) evaluated the effectiveness of 70 blood centers in the United States to determine the maximum possible improvement in operational efficiency. It seems that increasing the national blood supply by increasing the operational efficiency can be an alternative to increasing the collection and production of blood products.

In this regard, Ghandforoush and Sen (13) presented a mixed-integer nonlinear programming model for minimizing the cost of planning for platelet production in a regional blood center. Duan and Liao (14) also proposed a new blood supply chain optimization framework to minimize the retirement date by considering a certain tolerable level of shortage. They developed a tabu-search algorithm to find near-optimal solutions in a reasonable 
computational time. Moreover, Sha and Huang (15) presented a multi-period mathematical programming model for blood supply in emergency situations after an earthquake in China. Their model determined the optimal number of locations, allocation of temporary blood facilities, operational costs, and shortage costs during planning horizons, regardless of the uncertainty of demand and the amount of blood donation. In this model, the coverage limit for temporary facilities was included. Based on these research trends, blood compatibility (16), blood supply optimization in disasters (17), blood wastage (18), blood bank location optimization $(19,20)$, and other aspects of the blood supply chain were investigated.

\section{Objectives}

The proper design of blood supply networks provides an optimal structure for efficient and effective management (21). Generally, a blood supply chain includes donors, mobile facilities, fixed facilities, regional centers, and hospitals. This study aimed to examine a system for collecting and distributing blood at strategic and tactical levels. It also aimed to present a mixed-integer linear programming (MILP) model for strategic and tactical decision-making of blood collection systems for a seven-year planning horizon. The collected blood was divided into six blood products, including blood, congested red blood cells, washed red blood cells, frozen red blood cells, platelets, and plasma. The main contributions of this paper can be described as follows:

Developing a multi-period MILP model for designing a blood supply chain network, considering temporary and fixed facilities for blood collection, foreign blood applicants, and donors;

Considering six blood products for different applicants; and

Applying the proposed model in a real case in Urmia, Iran.

In this study, a simple yet effective mathematical model was developed for the local blood supply chain management. Given the importance of proper distribution of blood and its products, managers need to develop a more detailed and specific decision-making scheme (22); this need can be met through a local supply chain (23). This study contributed to the literature on blood supply chain optimization and local blood bank planning.

\section{Methods}

In this study, fixed blood collection centers, including hospitals, along with temporary blood collection sites and blood donors, were considered in the local blood supply chain. The possibility of blood product exports and imports was also taken into consideration, and a real-life case study of Urmia City was executed with the proposed model. After blood collection from donors, the collected blood was transferred to blood banks for testing and procurement of blood products. If any shortage occurred, blood banks could engage in importing blood from neighboring provinces, and vice versa. The following are the main assumptions of the proposed model:

Facilities include fixed and temporary blood donation facilities and blood banks.

Parameters are considered to be deterministic.

Blood is broken down into six different sub-products.

Exports and imports are possible, considering the blood inventory level in the region.

The planning horizon is a seven-year period for regional facilities.

To understand the proposed model, it is preferable to analyze the supply chain network scheme, as depicted in Figure 1. The proposed network consisted of blood donor groups (BD), temporary blood donation facilities (TBF), main blood facilities (MBF), blood banks (BB), blood supply and processing centers (PPC), and possible foreign clients; BDs donate TBFs or MBFs. TBFs transfer blood to both MBFs and BBs. BBs test, examine, store, and ultimately distribute blood and its derivatives. For preserving blood and extending its life cycle, in processing centers, blood was broken into six blood products, including complete blood with a maximum shelf life of 35 days, condensed red blood cells with a shelf life of up to 42 days, washed red blood cells with a retention time of 24 hours, frozen red blood cells with a maximum retention time of 14 days, platelets with a shelf life of five days, and finally, fresh frozen plasma with a shelf life of one year; this procedure enabled imports and exports.

The objective function of the proposed model was to minimize the fixed cost of facility setup, transportation costs, blood operational costs, blood product-related costs, allocation decision-related costs for temporary and fixed facilities, and finally, blood imports/exports. The indices, parameters, and variables of the proposed model are described below.

The indices and sets include:

$$
\begin{aligned}
& \mathrm{i} \text { : Index of } \mathrm{BD}, \mathrm{i}=1,2, \ldots, \mathrm{I} \\
& \mathrm{j} \text { : Index of } \mathrm{TBF}, \mathrm{j}=1,2, \ldots, \mathrm{J} \\
& \mathrm{k} \text { : Index of } \mathrm{MBF}, \mathrm{k}=1,2, \ldots, \mathrm{K} \\
& \mathrm{w} \text { : Index of } \mathrm{BB}, \mathrm{w}=1,2, \ldots, \mathrm{W} \\
& \mathrm{p} \text { : Index of blood products, } \mathrm{p}=1,2, \ldots, \mathrm{P} \\
& \text { t: Index of planning horizon, } \mathrm{t}=1,2, \ldots, \mathrm{T}
\end{aligned}
$$




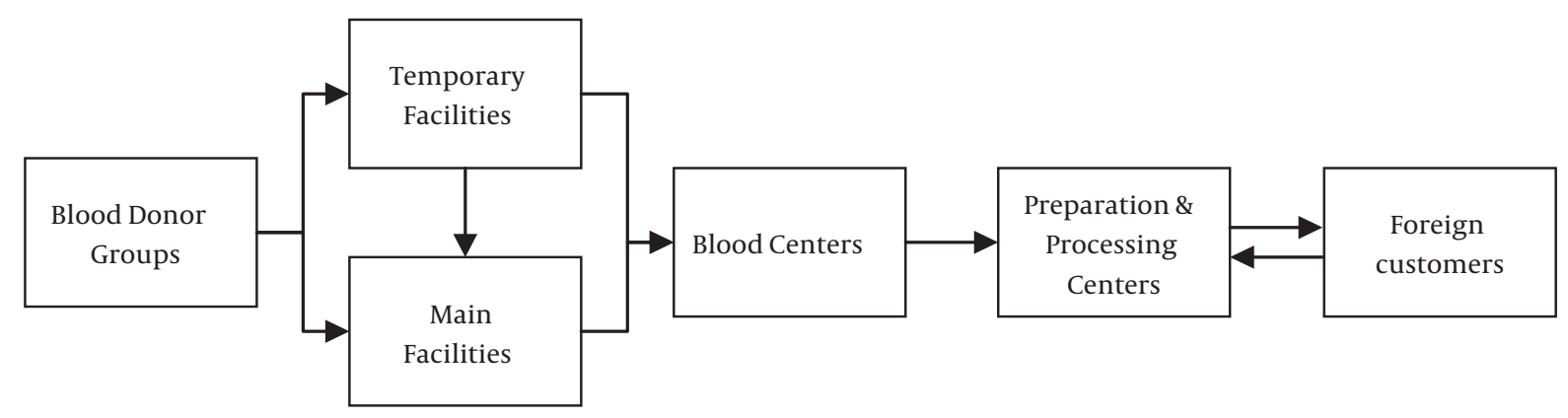

Figure 1. Blood Supply Chain Network

The parameters include:

$\mathrm{FC}_{\mathrm{kt}}$ : Fixed cost in location $\mathrm{k}$ in period $\mathrm{t}$.

$\mathrm{TCk}_{\mathrm{wt}}$ : Blood transfusion cost from location $\mathrm{k}$ to BB w in period $\mathrm{t}$.

$\mathrm{DC}_{\mathrm{jkt}}$ : Blood supply cost from TBF $\mathrm{j}$ to BMF $\mathrm{k}$ in period $\mathrm{t}$.

$\mathrm{TC}_{j_{\mathrm{ww}}}$ : Blood transfusion cost from TBF $\mathrm{j}$ to $\mathrm{BB} w$ in period t.

$\mathrm{HC}_{\mathrm{w}}$ : Blood maintaining cost in $\mathrm{BB}$ w.

$\mathrm{D}_{\mathrm{kt}}$ : Demand in BMF k in period $\mathrm{t}$.

$\mathrm{r}_{\mathrm{ij}}$ : Distance between BD i and TBF $\mathrm{j}$.

$\mathrm{r}_{\mathrm{ik}}$ : Distance between BD i and BMF k.

$r_{0}$ : The maximum coverage of a TBF (if $r_{i j} \leq r_{0}$ i is covered by $\mathrm{j}$ ).

$r 1_{0}$ : The maximum coverage of a BMF (if $\mathrm{rr}_{\mathrm{ik}} \leq \mathrm{r} 1_{0} \mathrm{i}$ is covered by k).

$\mathrm{Ct}_{\mathrm{j} \mathrm{t}}$ : Capacity of TBF $\mathrm{j}$ in period $\mathrm{t}$.

$\mathrm{Cm}_{\mathrm{kt}}$ : Capacity of MBF k in period $\mathrm{t}$.

$\mathrm{g}_{\mathrm{it}}$ : Capacity of BD $\mathrm{i}$ in period $\mathrm{t}$.

$\mathrm{FC}_{\mathrm{j} t}$ : Fixed cost of allocating a TBF at location $\mathrm{j}$ in period t.

$\mathrm{FC}_{\mathrm{wt}}$ : Fixed cost of allocating a BB at location $\mathrm{w}$ in period t.

$\mathrm{PC}_{\mathrm{pwt}}$ : Production cost of blood product in $\mathrm{BB} \mathrm{w}$ in period t.

$\mathrm{D} 2_{\mathrm{pwt}}$ : Demand for blood product $\mathrm{p}$ in $\mathrm{BB} w$ in period $\mathrm{t}$.

$A C_{i j t}$ : Allocation cost of BD i to $T B F j$ in period $t$.

$\mathrm{AC}_{1 \mathrm{ikt}}$ : Allocation cost of $\mathrm{BD} \mathrm{i}$ to $\mathrm{BMF} \mathrm{k}$ in period $\mathrm{t}$.

$\mathrm{ExB}_{\mathrm{pt}}$ : Export income of blood product $\mathrm{p}$ in period $\mathrm{t}$.

$\mathrm{Ca}_{\mathrm{pwt}}$ : Capacity for blood product $\mathrm{p}$ in $\mathrm{BB} \mathrm{w}$ in period $\mathrm{t}$.

$\alpha_{\mathrm{p}}$ : Conversion factor for blood product $\mathrm{p}$.

$\mathrm{ImC}_{\mathrm{p} t}$ : Importing cost of blood product $\mathrm{p}$ in period $\mathrm{t}$.

The variables include:

Im1 $\mathrm{kt}_{\mathrm{k}}$ : Blood imports to fixed facility $\mathrm{k}$ in period $\mathrm{t}$.

$V_{\text {ikt }}$ : Donated blood from BD i to BMF $\mathrm{k}$ in period $\mathrm{t}$.

$\mathrm{V}_{\mathrm{j} k \mathrm{kt}}$ : Blood of TBF $\mathrm{j}$ at BMF $\mathrm{k}$ in period $\mathrm{t}$.

$\mathrm{V} 2_{\mathrm{ijj}}$ : Blood of BD $\mathrm{i}$ in TBF $\mathrm{j}$ in period $\mathrm{t}$. $\mathrm{q}_{\mathrm{ijt}} \mathrm{t} 1$, if BD $\mathrm{i}$ is assigned to BTF $\mathrm{j}$ in period $\mathrm{t}$; otherwise 0 .

$\mathrm{q} 1_{\text {ikt }}: 1$, if $\mathrm{BD} \mathrm{i}$ is assigned to MBF $\mathrm{k}$ at time $\mathrm{t}$; otherwise 0 .

$\mathrm{x}_{\mathrm{k}}: 1$, if an MBF is located at location $\mathrm{k}$; otherwise 0.

$\mathrm{x1}_{\mathrm{j} \mathrm{t}}: 1$, if a TBF is located at location $\mathrm{j}$ in period $\mathrm{t}$; otherwise 0 .

$\mathrm{Ex}_{\mathrm{pwt}}$ : Export of blood product $\mathrm{p}$ from $\mathrm{BB} \mathrm{w}$ in period $\mathrm{t}$.

I $2_{\text {pwt }}$ : The inventory level of blood product p in BB w in period t.

$\mathrm{U}_{\mathrm{jwt}}$ : Collected blood from TBF $\mathrm{j}$ to BB w in period t.

$\mathrm{Y}_{\mathrm{kwt}}$ : Collected blood from MBF $\mathrm{k}$ to BB w in period $\mathrm{t}$.

$\mathrm{x} 2_{\mathrm{w}}: 1$, if $\mathrm{BB}$ is opened in $\mathrm{w}$; otherwise, 0 .

$\mathrm{BP}_{\mathrm{pwt}}$ : The amount of blood product $\mathrm{p}$ in $\mathrm{BB}$ w in period t.

$\operatorname{Im}_{\text {pwt }}:$ Import of blood product $\mathrm{p}$ to BB $\mathrm{w}$ in period $\mathrm{t}$.

$\mathrm{I} 1_{\mathrm{kt}}$ : The fixed asset inventory level at candidate location $\mathrm{k}$ in period $\mathrm{t}$.

The objective function is:

Equation 1 indicates the objective function of the proposed model. The fixed setup cost of both TBFs and $\mathrm{BBs}$, blood testing and processing costs, and $\mathrm{BD}$ and $\mathrm{TBF}$ allocation costs were considered, along with the transportation costs, blood sub-products, and cost/profit of import/export. 


$$
\begin{aligned}
\text { Min } Z= & \sum_{j, t} F C 1_{j t} X 1_{j t}+\sum_{k, t} F C_{k t} X_{k} \\
& +\sum_{j, k, t} D C_{j k t} V 1_{j k t}+\sum_{j, w, t} T C 1_{j w t} U_{j w t} \\
& +\sum_{k, w, t} T C_{k w t} Y_{k w t}+\sum_{p, w, t} H C_{w} I 2_{p w t} \\
& +\sum_{p, w, t} P C_{p w t} B P_{p w t}+\sum_{w, t} F C 2_{w t} X 2_{w} \\
& +\sum_{i, j, t} A C_{i j t} r_{i j} q_{i j t}+\sum_{i, k, t} A C 1_{i k t} r 1_{i k} q 1_{i k t} \\
& +\sum_{p, w, t} I m C_{p t} I m_{p w t}-\sum_{p, w, t} E x B_{p t} E x_{p w t}
\end{aligned}
$$

The constraints included:

$$
\begin{aligned}
& I 2_{p w, t-1}+B P_{p w t}-I 2_{p w t}-E x_{p w t}=D 2_{p w t} ; \forall p, w, t(2) \\
& I 1_{k, t-1}+\sum_{j} V 1_{j k t}+\sum_{i} V_{j k t}-I 1_{k t}-\sum_{w} Y_{k w t} \\
& \quad=D 1_{k t} ; \forall k, t
\end{aligned}
$$$$
\sum_{j} V 1_{j k t}+\sum_{i} V_{i k t} \leq C m_{k t} X_{k}
$$$$
\sum_{k} V_{j k t}+\sum_{j} V 2_{i j t} \leq g_{i t} ; \forall i, t
$$

$\sum_{i} V 2_{i j t} \leq C t_{j t} X 1_{j t} ; \forall j, t$

$\sum_{i} V 2_{i j t}=\sum_{k} V 1_{j k t}+\sum_{w} U_{j w t} ; \forall j, t$

$r_{i j} q_{i j t} \leq r_{0} ; \forall i, j, t$

$r 1_{i k} q 1_{i k t} \leq r 1_{0} ; \forall i, k, t$

$U_{j w t} \leq M . q_{i j t} ; \forall i, j, w, t$

$Y_{k w t} \leq M . q 1_{i k t} ; \forall i, k, w, t$

$q_{i j t} \leq x 1_{j t} ; \forall i, j, t$

$q 1_{i k t} \leq X_{k} ; \forall i, k, t$

$\sum_{j} \alpha_{p} U_{j w t}+\sum_{k} \alpha_{p} Y_{k w t} \leq C a_{p w t} X 2_{w} ; \forall p, w, t$

$\sum_{j} \alpha_{p} U_{j w t}+\sum_{k} \alpha_{p} Y_{k w t}=B P_{p w t} ; \forall p, w, t$
$I m_{p w t}, I m 1_{k t}, V_{i k t}, V 1_{j k t}, V 2_{i j t}, U_{j w t}$,

$E x_{p w t}, I 1_{k t}, I 2_{p w t}, Y_{k w t}, B P_{p w t} \geq 0$

$q_{i j t}, q 1_{i k t}, X_{k}, X 1_{j t}, X 2_{w} \in\{0,1\}$

$\forall i, j, k, w, p, t$

Constraints 2 and 3 ensure the material flow balance in opened facilities throughout the planning horizon. Constraints 4 to 6 are the capacity constraints. Constraint 7 ensures the blood flow balance. Constraints 8 and 9 ensure the coverage distance limit. Constraints 10 and 11 indicate the material flow requirements. Constraint 12 and 13 are the allocation restrictions. Constraint 14 is the capacity limit for BBs, and constraint 15 is the blood flow balance in BBs. Finally, constraint 16 is the non-negativity and binary restrictions of variables.

\section{Results}

To engage in the numerical analysis of the proposed model, demand values were estimated based on the population of the case study region (Urmia), which was extracted from the national population and housing census in 2011 (https://www.amar.org.ir/Portals/1/Iran/90.pdf). For demand estimation, the estimator should consider several factors for more realistic and reliable results (24). Table 1 shows the blood demand in different periods, and Table 2 presents the fixed costs for establishing facilities.

A case study of Urmia city was conducted to evaluate the adaptability and functionality of the proposed model. Urmia roughly has a population of 667,000 people, and the blood demand is met through two channels, that is, TBFs and MBFs. The number of BDs was considered with regard to the number of urban districts in Urmia. There are seven hospitals in Urmia, and there are ten TBFs available. After data collection, the proposed model was coded in GAMS 24 optimization software using a CPLEX optimizer, and all executions were implemented on a Corei7 $2.40 \mathrm{GHz}$ laptop with $8 \mathrm{~GB}$ of RAM. The optimal quantities are presented below.

Table 3 indicates the export values for different blood products throughout the planning horizon. It can be concluded that the export quantity of products with long-lived plasma and dense red blood cells was much higher than other products. The average volume of donated blood to TBFs was about one million blood units in each period. Interestingly, TBFs were assigned to BBs and not MBFs (hospitals). Considering the capacity considerations, the 


\begin{tabular}{|c|c|c|c|c|c|c|c|}
\hline D1kt & & & & Period & & & \\
\hline $\mathbf{k}$ & 1 & 2 & 3 & 4 & 5 & 6 & 7 \\
\hline 2 & 2350000 & 2726000 & 2720000 & 2790000 & 2504000 & 2782000 & 2700000 \\
\hline 3 & 2420000 & 2807000 & 2787000 & 2832000 & 2699000 & 2825000 & 2799000 \\
\hline 4 & 2470000 & 2865000 & 2852000 & 2896000 & 2700000 & 2889000 & 2865000 \\
\hline 6 & 2450000 & 2842000 & 2829000 & 2859000 & 2762000 & 2853000 & 2835000 \\
\hline 7 & 2440000 & 2830000 & 2804000 & 2847000 & 2785000 & 2838000 & 2807000 \\
\hline \multicolumn{8}{|c|}{ Table 2. The Fixed Cost of Facilities } \\
\hline FCkt & & & & Period & & & \\
\hline $\mathbf{k}$ & $\mathbf{1}$ & 2 & 3 & 4 & 5 & 6 & 7 \\
\hline 2 & 2150000 & 2472500 & 2795000 & 3117500 & 3430000 & 3730200 & 4022930 \\
\hline 3 & 1950000 & 2242500 & 2535000 & 2825500 & 3118000 & 3411000 & 3701350 \\
\hline 4 & 1450000 & 1667500 & 1885000 & 2101500 & 2319500 & 2537100 & 2752350 \\
\hline 5 & 2350000 & 2702500 & 3055000 & 3407000 & 3759200 & 4110170 & 4462320 \\
\hline 6 & 3150000 & 3622500 & 4094500 & 4566060 & 5038900 & 5511100 & 5981350 \\
\hline 7 & 3698100 & 4252500 & 4806060 & 5360600 & 5914600 & 6462900 & 7023300 \\
\hline \multicolumn{8}{|c|}{ Table 3. Blood Exports } \\
\hline \multirow{2}{*}{$\mathbf{p}$} & \multicolumn{7}{|c|}{ Period } \\
\hline & 1 & 2 & 3 & 4 & 5 & 6 & 7 \\
\hline $\mathbf{1}$ & 2943700 & 2867000 & 2900400 & 3250500 & 2927600 & 2891700 & 484400 \\
\hline 2 & 1326200 & 1279200 & 1260000 & 1441200 & 1307000 & 1242200 & 68400 \\
\hline 3 & 867500 & 819100 & 821600 & 0 & 1758600 & 760150 & 0 \\
\hline 4 & 861200 & 811900 & 813500 & 938000 & 832500 & 743950 & 0 \\
\hline 5 & 0 & 0 & 0 & 0 & 0 & 0 & 0 \\
\hline 6 & 1133700 & 1086200 & 1089500 & 1242900 & 1094700 & 1083400 & 6400 \\
\hline
\end{tabular}

donated blood quantity to the fixed facilities was much higher than temporary facilities.

The production values of different blood products are presented in Table 4. Based on the results, production quantities are almost stable for each product, and their values do not fluctuate severely throughout the planning horizon.

\subsection{Sensitivity Analysis}

To investigate the sensitivity of the obtained optimal results, a series of sensitivity analyses on the key parameters was executed. In Figure 2 to Figure 4, different parameters are analyzed in the spectrum of $20 \%$ down to $20 \%$ up.

Figure 2 shows the objective function values under different blood product demands. As expected, the objective function values created a gentle curve as the demand values increased. In contrast with the fixed facility costs, transportation costs from fixed facilities to blood banks, as depicted in Figure 3, showed major changes in the interval

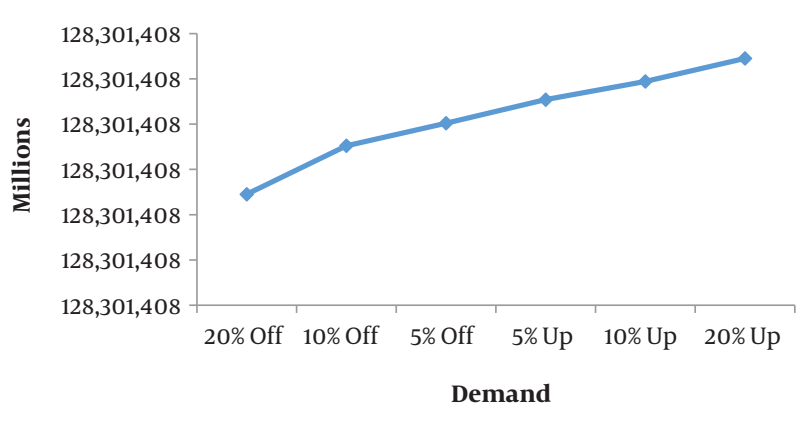

Figure 2. Objective function values under different demand values

of $\pm 5 \%$. Beyond this interval, fluctuations were very gentle and smooth. According to Figure 4, the objective function values behaved smoothly at a higher cost parameter as compared to lower blood bank costs. 


\begin{tabular}{|c|c|c|c|c|c|c|c|}
\hline \multirow{2}{*}{$\mathbf{p}$} & \multicolumn{7}{|c|}{ Period } \\
\hline & 1 & 2 & 3 & 4 & 5 & 6 & 7 \\
\hline 1 & 3240000 & 3240000 & 3240000 & 3600000 & 3240000 & 3240000 & 811800 \\
\hline 2 & 1620000 & 1620000 & 1620000 & 1800000 & 1620000 & 1620000 & 405900 \\
\hline 3 & 1170000 & 1170000 & 1170000 & 1300000 & 1170000 & 1170000 & 293150 \\
\hline 4 & 1170000 & 1170000 & 1170000 & 1300000 & 1170000 & 1170000 & 293150 \\
\hline 5 & 360000 & 360000 & 360000 & 400000 & 360000 & 360000 & 90200 \\
\hline 6 & 1440000 & 1440000 & 1440000 & 1600000 & 1440000 & 1440000 & 360800 \\
\hline
\end{tabular}

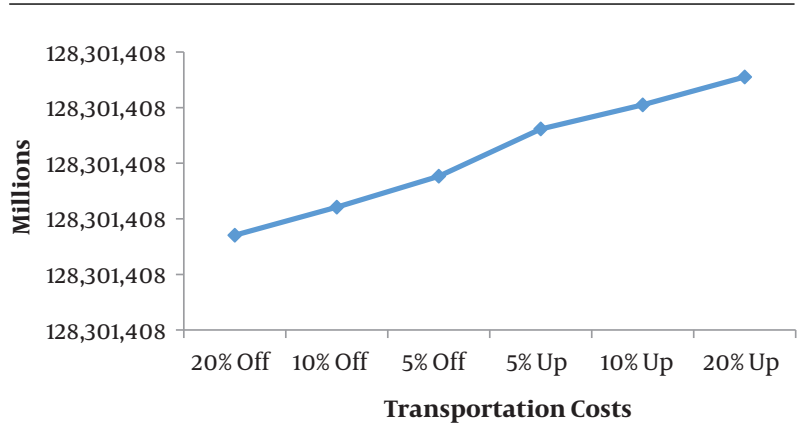

Figure 3. Objective function values under different transportation costs

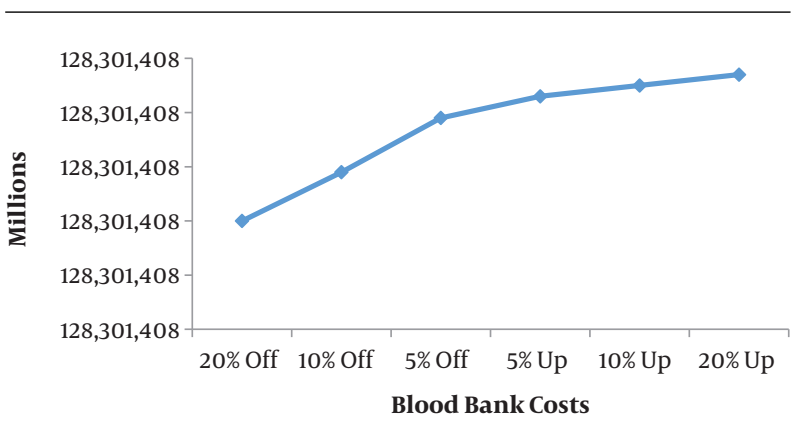

Figure 4. Objective function values under different blood bank costs

\section{Conclusions}

In this study, after a brief review of the design problems of blood supply chain networks and introduction of their different components, including blood donors, fixed and temporary blood donation facilities, blood banks, and procurement centers, a local blood supply chain model was proposed, based on the MILP model. A striking issue in the blood supply chain network design is the corruptibility and perishable nature of blood. In the proposed model, the collected blood was divided into six sub-products (complete blood, congested red blood cells, washed red blood cells, frozen red blood cells, platelets, and plasma). Consid- ering the aforementioned, the proposed model could provide managers with a practical mathematical model.

In this study, a new application of health research was presented. In recent years, operation research has been widely used to design and plan healthcare. In this study, the combination of health and emergency supply chain was studied, which to some extent distinguished the features of the problem from other issues in the supply chain. In this study, all parameters were considered as deterministic. However, consideration of real-world uncertainties can be an interesting future research avenue. Also, attention to blood supply varieties among blood donors and their abundance or infrequency can be an interesting research topic. Finally, demand propagation in disaster and relief programs can be considered in future studies.

\section{Footnotes}

Authors' Contribution: All authors contributed to different sections of the paper.

Conflict of Interests: The authors declare that they have no conflict of interest.

Funding/Support: This study did not receive any funding.

\section{References}

1. Ekici A, Özener OÖ, Çoban E. Blood Supply Chain Management and Future Research Opportunities. Operations Research Applications in Health Care Management. 2018. p. 241-66. doi: 10.1007/978-3-319-654553_10.

2. Habibi-Kouchaksaraei M, Paydar MM, Asadi-Gangraj E. Designing a biobjective multi-echelon robust blood supply chain in a disaster. Appl Math Model.2018;55:583-99. doi:10.1016/j.apm.2017.11.004.

3. Jabbarzadeh A, Fahimnia B, Seuring S. Dynamic supply chain network design for the supply of blood in disasters: A robust model with real world application. Transport Res Part E. 2014;70:225-44. doi: 10.1016/j.tre.2014.06.003. 
4. Tabatabaie M, Ardalan A, Abolghasemi H, Holakouie Naieni K, Pourmalek F, Ahmadi B, et al. Estimating blood transfusion requirements in preparation for a major earthquake: the Tehran, Iran study. Prehosp Disaster Med. 2010;25(3):246-52. doi:10.1017/s1049023x00008116. [PubMed: 20586006].

5. Yamazaki F, Yano Y, Matsuoka M. Visual Damage Interpretation of Buildings in Bam City using QuickBird Images following the 2003 Bam, Iran, Earthquake. Earthquake Spectra. 2019;21(1_suppl):329-36. doi: 10.1193/1.2101807.

6. Beliën J, Forcé H. Supply chain management of blood products: A literature review. Eur J Oper Res. 2012;217(1):1-16. doi: 10.1016/j.ejor.2011.05.026.

7. Osorio AF, Brailsford SC, Smith HK. A structured review of quantitative models in the blood supply chain: a taxonomic framework for decision-making. Int J Product Res. 2015;53(24):7191-212. doi: 10.1080/00207543.2015.1005766.

8. Farahani RZ, Rezapour S, Drezner T, Fallah S. Competitive supply chain network design: An overview of classifications, models, solution techniques and applications. Omega. 2014;45:92-118. doi: 10.1016/j.omega.2013.08.006.

9. Sabbaghnia A, Razmi J, Babazadeh R, Moshiri B. Reducing the Bullwhip effect in a supply chain network by application of optimal control theory. RAIRO - Oper Res. 2018;52(4-5):1377-96. doi: 10.1051/ro/2018025.

10. Rabbani M, Sabbaghnia A, Mobini M, Razmi J. A graph theorybased algorithm for a multi-echelon multi-period responsive supply chain network design with lateral-transshipments. Opera Res. 2018;20(4):2497-517. doi: 10.1007/s12351-018-0425-y.

11. Pereira A. Economies of scale in blood banking: a study based on data envelopment analysis. Vox Sang. 2006;90(4):308-15. doi: 10.1111/j.14230410.2006.00757.x. [PubMed: 16635074].

12. Pitocco C, Sexton TR. Alleviating blood shortages in a resourceconstrained environment. Transfusion. 2005;45(7):1118-26. doi: 10.1111/j.1537-2995.2005.00176.x. [PubMed: 15987356].

13. Ghandforoush P, Sen TK. A DSS to manage platelet production supply chain for regional blood centers. Decis Support Sys. 2010;50(1):32-42. doi: 10.1016/j.dss.2010.06.005.

14. Duan Q, Liao T. Optimization of blood supply chain with shortened shelf lives and ABO compatibility. Int J Product Econom. 2014;153:113-29. doi: 10.1016/j.ijpe.2014.02.012.

15. Sha Y, Huang J. The Multi-period Location-allocation Problem of Engineering Emergency Blood Supply Systems. Sys Engin Proced. 2012;5:218. doi:10.1016/j.sepro.2012.04.004.

16. Zahiri B, Pishvaee MS. Blood supply chain network design considering blood group compatibility under uncertainty. Int J Product Res. 2016;55(7):2013-33. doi: 10.1080/00207543.2016.1262563.

17. Salehi F, Mahootchi M, Husseini SMM. Developing a robust stochastic model for designing a blood supply chain network in a crisis: a possible earthquake in Tehran. Ann Operat Res. 2017;283(1-2):679-703. doi: 10.1007/s10479-017-2533-0.

18. Yates N, Stanger S, Wilding R, Cotton S. Approaches to assessing and minimizing blood wastage in the hospital and blood supply chain. ISBT Sci Series. 2017;12(1):91-8. doi: 10.1111/voxs.12330.

19. Kaveh A, Ghobadi M. A Multistage Algorithm for Blood Banking Supply Chain Allocation Problem. Int J Civil Engin. 2016;15(1):103-12. doi: 10.1007/s40999-016-0032-3.

20. Heydari J, Sabbaghnia A, Razmi J. A dynamic bi-objective model for after disaster blood supply chain network design; a robust possibilistic programming approach. J Industr Sys Engin. 2018;11(Special Issue):1628.

21. Kuruppu KK. Management of blood system in disasters. Biologicals. 2010;38(1):87-90. doi: 10.1016/j.biologicals.2009.10.005. [PubMed: 20149686].

22. Albino V, Izzo C, Kühtz S. Input-output models for the analysis of a local/global supply chain. Int J Product Econom. 2002;78(2):119-31. doi: 10.1016/s0925-5273(01)00216-x.

23. Christopher M. Logistics \& supply chain management. Pearson UK; 2016.

24. Razmi J, Sabbaghnia A. Tracing the impact of non-uniform forecasting methods on the severity of the bullwhip effect in two- and threelevel supply chains. Int J Manag Sci Engin Manag. 2015;10(4):297-304. doi: $10.1080 / 17509653.2015 .1016132$. 